\title{
Warna Lokal Aceh dan Konflik dalam Naskah Drama "Tanah Perempuan" Karya Helvy Tiana Rosa
}

\author{
Dwi Nurcahyo ${ }^{1)}$ \\ Universitas Indraprasta PGRI \\ Jalan Nangka No. 58 C/TB. Simatupang, Tanjung Barat, Jakarta Selatan 12530 \\ Dendy Sugono ${ }^{2)}$ \\ Universitas Indraprasta PGRI \\ Jalan Nangka No. 58 C/TB. Simatupang, Tanjung Barat, Jakarta Selatan 12530- \\ dnurcahyo87@gmail.com ${ }^{1)}$,dsugono@yahoo.com ${ }^{2)}$
}

\begin{abstract}
The research aimed to identify the local color of Aceh and the conflict in the drama script "Tanah Perempuan" by Helvy Tiana Rosa. The approach used in this research is literary analytical. The research method uses descriptive methods, analyzing the content to describe objects and phenomena that are manifested in a narrative writing. From the research results, it can be concluded that the most types of conflict found are human conflicts with other humans $75.7 \%$. Conflict between humans and themselves (mind) is $10 \%$ and humans and nature are found in $8.6 \%$. Meanwhile, the least conflict found was human conflict with society or community as much as $5.7 \%$. The local Acehnese color, the Acehnese language element, is mostly found at $40.4 \%$. Local religious color $38.5 \%$. Local color technology systems and equipment $9.6 \%$ and livelihood systems $7.7 \%$. The local color of the organizational system 3,8\%. Research results are useful for students, teachers, students, literature lovers and humanists.
\end{abstract}

Keywords : Local Color, Conflict, Drama, Tanah Perempuan, Aceh

\begin{abstract}
Abstrak
Penelitian bertujuan mengidentifikasi warna lokal Aceh dan konflik dalam naskah drama "Tanah Perempuan" karya Helvy Tiana Rosa. Pendekatan yang dipakai dalam penelitian adalah analitis sastra. Metode penelitian menggunakan metode deskriptif, menganalisis isi untuk mendeskripsikan objek dan fenomena yang terejewantah dalam suatu tulisan yang bersifat naratif. Dari hasil penelitian dapat ditarik kesimpulan jenis konflik terbanyak ditemukan adalah konflik manusia dengan manusia lain 75,7 \%. Konflik manusia dengan dirinya (batin) $10 \%$ dan manusia dengan alam ditemukan 8,6\%. Sedangkan konflik ang paling sedikit ditemukan adalah konflik manusia dengan masyarakat atau komunitas sebanyak 5,7 \%. Warna lokal Aceh unsur bahasa Aceh paling banyak ditemukan 40,4\%. Warna lokal religi 38,5\%. Warna lokal sistem teknologi dan peralatan 9,6\% dan sistem pencaharian 7,7 \%. Warna lokal sistem organisasi 3,8 \%. Hasil Penelitian bermanfaat untuk mahasiswa, guru, siswa, dan pecinta sastra serta budayawan.
\end{abstract}

Kata Kunci: Warna lokal, Konflik, Drama, Tanah Perempuan, Aceh

\section{PENDAHULUAN}

Drama merupakan bagian dari karya sastra yang mempunyai ciri khas. Rentetan dialog dari tokoh-tokohnya menjadi daya tarik tersendiri bagi penikmat sastra. Penulis naskah drama pun tidak sebanyak penulis novel, cerpen ataupun puisi. Hal itulah yang membuat naskah drama beserta penulisnya mempunyai 
keunikannya. Berkaitan dengan keunikan drama, Minderop (2005:22) mengatakan bahwa dialog yang ditampilkan drama juga dapat membaca karakter setiap tokohtokohnya. Karakterisasi dialog drama diklasifikasikan menjadi jatidiri penutur, lokasi, jatidiri tokoh, situasi percakapan, perkataan penutur, jatidiri tokoh yang dituju penutur, nada suara, kualitas mental, dialek, kosakata, dan penekanan. Dengan kata lain dialog dalam drama menjadi hal yang paling vital dalam karya tersebut karena merupakan perwujudan isi cerita yang dibawakan oleh tokohtokohnya dengan berbagai watak yang melekat.

Pengkajian naskah drama pada umumnya dapat dilakukan dengan berbagai analisis. Analisis dapat membedah drama melalui unsur intrinsik dan ekstrinsik. Dengan kata lain analisis naskah drama sangatlah menarik karena dapat dianalisis dengan berbagai bedahan teori sastra. Dalam pengkajian sastra di Indonesia, memang belum banyak yang melakukan analisis naskah drama sebagai objeknya. Kebanyakan para peneliti sastra yang sudah meneliti naskah drama pun hanya membedah unsur intrinsik atau ekstrinsik saja.

Apreasiasi kritik sastra terutama drama sangat memungkinkan dilakukan dengan berbagai pendekatan. Salah satu sastrawan Indonesia yang multitalenta karena menulis berbagai karya sastra seperti cerpen, puisi, novel, hingga naskah drama adalah Helvy Tiana Rosa. Sastrawan kelahiran Medan ini menjadi penulis serba bisa yang cukup dikenal oleh masyarakat pecinta sastra di Indonesia. Salah satu karya sastra Helvy Tiana Rosa adalah naskah drama yang sudah dibukukan berjudul "Tanah Perempuan: Drama Tragedi Sembilan Babak". Buku naskah drama yang diterbitkan Lapena tahun 2006 ini cukup dikenal karena banyak dipentaskan oleh teater-teater di Indonesia.

Naskah drama "Tanah Perempuan" merupakan naskah pementasan drama yang sangat kental dengan budaya dan situasi Aceh sekitar tahun 2000. Buku ini bercerita mengenai perjuangan sosok perempuan yang mengalami berbagai konflik internal dan eksternal dalam memperjuangkan hidupnya. Peristiwa besar yang terjadi seperti adanya operasi militer Indonesia ke Aceh untuk memerangi Gerakan Aceh Merdeka atau GAM. Hal itu membuat kondisi serba mencekam diberbagai tempat di Aceh karena terjadi banyak pembunuhan dan penculikan. Peristiwa besar lain adalah adanya bencana alam gempa disertai tsunami yang meluluh-lantahkan bumi serambi mekah tersebut.

Penelitian mengenai kajian budaya atau warna lokal sebuah daerah masih dikatakan langka di Indonesia. Padahal Indonesia mempunyai ciri khas budaya atau warna lokal yang begitu banyak di tiap daerahnya yang dapat dipadukan dengan penelitian sastra itu sendiri. Faruk (2012:74) mengatakan bahwa kajian-kajian budaya merupakan kritik sastra dengan rentangan objek dan pendekatan yang amat cair dan dinamis, yang dapat menyerap pendekatan apapun yang dapat ia gunakan dalam membahas suatu persoalan. Dengan pendekatan tersebut, kajian-kajian budaya berusaha membuat deskripsi mengenai proses sosial dan kultural yang berlangsung dalam proses produksi wacana, termasuk produksi karya sastra. Kentalnya warna budaya Aceh yang terdapat dalam naskah drama tersebut mengindikasikan bahwa sebuah kajian kritik sastra cukup dekat dengan kebudayaan manusia itu sendiri. 
Ratna (2007:19) mengatakan bahwa sastra dan kebudayaan tidak dapat dilepaskan dalam persoaalan kehidupan manusia. Menurut Nyoman, sebagai multidisiplin, studi kultural dibangun atas dasar kompetensi sastra dan kebudayaan, sedangkan kedua displin ilmu pada dasarnya sudah memiliki berbagai bidang kajian tertentu, bahkan dengan metode dan teori tersendiri. Mempelajari unsur-unsur budaya merupakan hal yang penting dalam memahami kebudayaan manusia itu sendiri.

Kluckhohn (1953:304-320) mengatakan bahwa kebudayaan yang ditemukan pada semua bangsa di dunia dari sistem kebudayaan yang sederhana seperti masyarakat pedesaan hingga sistem kebudayaan yang kompleks seperti masyarakat perkotaan. Kluckhon membagi sistem kebudayaan dalam tujuh bagian yaitu kesenian, sistem peralatan dan teknologi, sistem mata pencaharian, sistem organisasi/kemasyarakatan, bahasa, sistem pengetahuan, religi, dan sistem mata pencaharian.

Kajian lain yang juga menarik dalam naskah drama "Tanah perempuan" adalah konflik. Menurut Pickering (2006:1) konflik terbagi menjadi 4 jenis yaitu manusia dengan diri sendiri, manusia dengan individu atau manusia lain, manusia dengan masyarakat, manusia dengan alam. Banyaknya konflik yang terjadi dan dialami oleh tokoh-tokoh dalam naskah drama "Tanah Perempuan" karya Helvy Tiana Rosa maka peneliti juga akan menganalisis berbagai konflik yang muncul dalam cerita naskah drama tersebut. Jenis konflik yang akan diteliti dalam tesis ini adalah konflik manusia dengan dirinya sendiri, konflik manusia dengan masyarakat, Konflik manusia dengan manusia lain, dan konflik manusia dengan alam. Keseluruhan konflik tersebut pun dapat dijadikan sebuah instrumen penelitian dalam penelitian sastra.

Dengan pemaparan di atas maka peneliti akan menggali berbagai jenis konflik dan warna budaya lokal Aceh yang muncul dalam buku naskah drama "Tanah Perempuan" karya Helvy Tiana Rosa. Peneliti menggunakan seluruh jenis konflik dalam menganalisis. Namun, pendekatan unsur budaya atau warna lokal, hanya menggunakan 5 unsur saja, yaitu bahasa, sistem teknologi dan peralatan, sistem pencaharian, sistem organisasi, dan sistem religi/kepercayaan.

\section{METODE}

Metode penelitian ini menggunakan metode deskriptif. Menurut Hikmat (2011:44) merupakan metode penelitian untuk membuat gambaran mengenai situasi atau kejadian, sehingga berkehendak mengedakan akumulasi data dasar. Dengan metode deskriptif, orang yang sedang menganalisis karya sastra diharuskan menuliskan fakta dengan mendeskripsikan data tersebut. Fakta atau data merupakan sumber informasi yang menjadi basisi analisis. Metode deskriptif digunakan peneliti untuk mendeskripsikan atau menggambarkan berbagai fenomena, atau setting sosial yang ditulis dalam bentuk teks naratif. Hal tersebut dapat dijelaskan bahwa naratif berarti mengumpulkan berbagai fakta, data yang dihimpun dalam bentuk teks tulisan atau gambar daripada angka-angka, dengan mendeskripsikan 
berbagai hal yang terjadi pada sastra yang diteliti secara objektif. Hal tersebut akan dijelaskan sesuai dengan fakta dan data yang ditemukan.

Tahapan penelitian ini meliputi tahapan prapenelitian, tahap pengumpulan data, tahap pengolahan data, hingga tahap penyusunan laporan hasil. Instrumen penelitian digunakan juga agar analisis dapat terdeskripsikan dengan baik. Tabel dibagi menjadi empat bagian, tabel pertama adalah tabel aspek konflik yang berisi nama tokoh, kutipan teks dan halamannya, serta jenis-jenis konfliknya. Tabel kedua merupakan matriks persentase aspek konflik yang berisi jumlah dan persentase. Tabel ketiga berisi aspek budaya Aceh yang terdiri dari kolom adegan/kutipan teks dan halaman, aspek budaya, serta kutipan teks, unsur budaya, dan halaman. Tabel keempat merupakan matriks persentase aspek budaya yang terdiri dari jumlah dan persentase.

\section{HASIL DAN PEMBAHASAN}

Hasil

Tabel 1. Matriks Presentase Aspek Konflik

\begin{tabular}{clcc}
\hline No & Jenis Konflik & Jumlah & Persentase \\
\hline 1 & Manusia dengan dirinya sendiri & $\mathbf{7}$ & $\mathbf{1 0} \%$ \\
2 & Manusia dengan manusia lain & $\mathbf{5 3}$ & $\mathbf{7 5 , 7 \%}$ \\
3 & Manusia dengan masyarakat & $\mathbf{4}$ & $\mathbf{5 , 7} \%$ \\
4 & Manusia dengan alam & $\mathbf{6}$ & $\mathbf{8 , 6} \%$ \\
& Jumlah & $\mathbf{7 0}$ & $\mathbf{1 0 0 \%}$ \\
\hline
\end{tabular}

Tabel 2. Matriks Persentase Aspek Budaya

\begin{tabular}{clcc}
\hline No & \multicolumn{1}{c}{ Aspek Budaya } & Jumlah & Persentase \\
\hline 1 & Bahasa & $\mathbf{2 1}$ & $\mathbf{4 0 , 4} \%$ \\
2 & Sistem Teknologi dan Peralatan & $\mathbf{5}$ & $\mathbf{9 , 6} \%$ \\
3 & Sistem Pencaharian & $\mathbf{4}$ & $\mathbf{7 , 7} \%$ \\
4 & Sistem Organisasi & $\mathbf{2}$ & $\mathbf{3 , 8} \%$ \\
5 & Sistem Religi & $\mathbf{2 0}$ & $\mathbf{3 8 , 5} \%$ \\
& Jumlah & $\mathbf{5 2}$ & $\mathbf{1 0 0} \%$ \\
\hline
\end{tabular}

\section{Pembahasan}

Naskah drama "Tanah Perempuan" adalah sebuah naskah drama yang ditulis oleh Helvy Tiana Rosa. Naskah ini sangat kental dengan latar belakang Aceh dan kisah nyata tentang bencana alam Tsunami yang sangat dahsyat serta permasalahan konflik antara Gerakan Aceh Merdeka (GAM) dengan pemerintah Indonesia. Berbagai suguhan latar budaya Aceh yang kental serta konflik yang sangat bervariasi membuat naskah drama ini sangat berbeda dari yang lainnya. 
Tokoh utama yang bernama Mala beserta anggota keluarganya yaitu Abu sebagai ayahnya, Mak sebagai ibuya, Majid sebagai suaminya, Agam sebagai anaknya, Imran sebagai adik kandungnya. Mala dan keluarganya ini menjadi pembawa alur cerita menuju berbagai konflik yang terjadi dalam naskah drama "Tanah Perempuan" ini.

Cerita berawal dari keluarga Mala yang kehilangan anggota keluarga mereka yang bernama Ma'e, abang Mala. Hal itulah menjadi awal mula kepedihan keluarga tersebut. Ma'e disebut-sebut hilang diculik oleh kelompok misterius karena dituduh ikut pemberontak yang mengupayakan kemerdekaan di bumi Aceh. Padahal nyatanya tidaklah seperti itu. Fakta lainnya memang di kampung tempat keluarga Mala tinggal, sering terjadi penculikan-penculikan yang modusnya sama.

Belum ikhlas atas penculikan Ma'e, keluarga Mala harus rela menerima kematian Abu, ayahnya yang ditembak. Peristiwa itu terjadi di depan rumah mereka dan dilakukan oleh kelompok misterius. Sejak kematian Abu, tokoh Imran terus mengusulkan kepada anggota keluarga agar pindah ke Penang untuk menghindari pembunuhan dan penculikan yang dilakukan oleh kelompok misterius. Namun keluarganya tidak setuju.

Tokoh Mak mengalami sedikit gangguan kesehatan dan psikologis karena kehilangan suaminya. Hal inilah yang membuat Majid, suami Mala pergi ke rumah Ibrahim yang berprofesi sebagai dokter. Namun ketika sampai di rumah Ibrahim, Majid malah ditangkap oleh kelompok yang mengaku polisi. Sejak malam itulah Majid tidak Kembali ke rumah. Hal tersebut membuat Mala terpukul dan kondisi Mak semakin memburuk. Imran tetap menawarkan pilihan untuk pindah, akan tetapi Mak dan Mala menolaknya dan menganjurkan Majid saja yang pindah. Pada akhirnya Imran pergi mengungsi ke Penang dengan bekal beberapa perhiasan Mak.

Mala, Mak, dan Agam hanya bertiga tinggal di rumahnya. Kondisi mereka pun semakin buruk secara psikologis. Tidak berapa lama berselang datanglah gempa bumi yang sangat dahsyat membuat kampung mereka bergetar hebat. Setelah gempa mereda, terdengar teriakan air naik air naik air naik dari orang-orang kampung. Sontak Mala, Mak, dan Agam ikut berlari mengikuti kerumunan warga yang mencari perlindungan diri ke dataran yang lebih tinggi.

Kemalangan Kembali menimpa Mala. Belum sempat ia sampai di dataran tinggi, gelombang Tsunami menghanyutkan Mala dan semua orang kampung yang berlari. Mala terpisah dengan Mak dan anaknya, Agam dan terseret arus gelombang yang menenggelamkannya bersama gelombang air laut yang menyapu jalanan. Setelah beberapa hari terdampar Mala ditolong oleh para relawan. Anehnya Mala tidak ingin relawan itu menolongnya. Mala terus mengutuk dirinya dan keadaan hingga ingin mengakhiri hidupnya saja karena merasa kehilangan semuanya.

Pada saat Mala berada di puncak titik frustasi, muncullah beberapa sosoksosok pahlawan Aceh terdahulu seperti Cut Nyak Dhien, Kemala Hayati, dll. Pada intinya semua pahlawan wanita Aceh tersebut sangat menginginkan Mala bangkit dari keterpurukan yang ada. Para pahlawan Aceh tersebut pun sempat mengutarakan kekecewaannya terhadap Mala karena Mala sempat ingin mengakhiri hidupnya. Pada akhirnya Mala dapat Bangkit dari keterpurukan yang melandanya. 
Mala akhirnya bangkit dan bertahan di pengungsian. Ia mengisi waktunya dengan membantu membangun Aceh yang telah hancur secara perlahan. Ia pun membantu meningkatkan psikologis para pengungsi terutama anak-anak. Pada suatu ketika Mala akhirnya bertemu dengan Agam, anaknya yang hilang tersapu gelombang Tsunami waktu itu. Keteguhan Mala ini membuatnya semakin semangat untuk mencintai Aceh dan mencoba berbuat semampunya untuk membangun Aceh kembali.

Pembahasan mengenai konflik dalam naskah drama "Tanah Perempuan" terdapat 4 aspek. Dari pemaparan tabel di atas dapat dipaparkan bahwa konflik manusia dengan dirinya sendiri berjumlah 7 data dengan presentase $10 \%$, konflik manusia dengan manusia lain sebanyak 53 dengan presentase $75,7 \%$, konflik manusia dengan masyarakat sebanyak 4 data dengan presentase $5,7 \%$, sedangkan manusia dengan alam sebanyak 6 data dengan presentase $8,6 \%$.

Konflik melibatkan berbagai tokoh dalam cerita seperti Mala, Abu, Mak, Imran, Majid, dan beberapa tokoh lainnya yang ada dalam cerita. Jumlah konflik yang yang ditemukan dalam naskah drama berjumlah 70 data yang telah dianalisis sesuai dengan jenis konfliknya. Konflik-konflik yang dianalisis merupakan konflik yang menyebar dari pembukaan drama hingga babak ke Sembilan.

Konflik manusia dengan dirinya sendiri muncul dalam cerita dengan berbagai sebab permasalahannya. Namun, tokoh utama Mala adalah tokoh dalam cerita yang paling sering dan paling banyak membawakan jenis konflik ini. Konflik ini dibawakan oleh tokoh Mala dan tokoh lainnya saat sedang gundah dan hampir putus asa menghadapi berbagai kejadian yang menimpa keluarganya serta musibah bencana alam Tsunami. Contoh penggalan teksnya seperti Lon tak mengerti, mengapa semua harus pergi? Mengapa santu persatu keluarga lon ambil? Mengapa? (Menggugat). Kini tak ada lagi alasan lon untuk hidup dan bertahan! Tak ada lagi! Tak kan pernah ada lagi! (BERTERIAK TAPI LEMAH, PUTUS ASA) (Rosa, 2006:18)

Konflik manusia dengan manusia lain muncul mendominasi dalam cerita naskah drama. Konflik ini muncul melibatkan berbagai tokoh seperti Mala dan Imran yang terbanyak. Tokoh-tokoh dalam cerita disebutkan mengalami pergulatan konflik satu dengan yang lainnya karena perbedaan pendapat pada masing-masing diri tokoh. Misalnya tokoh Mala dan keluarganya yang awalnya menentang tokoh Imran untuk hijrah ke Penang demi menghindari menjadi korban penculikan atau pembunuhan. Contoh penggalan teksnya seperti Memang tak ada jalan lain, Cut Kak. Kita bukan saja harus meninggalkan rumah ini, tapi harus meninggalkan Aceh. Firasat lon mengatakan semakin lama kita di sini, akan semakin banyak kemalangan dan kepedihan yang menimpa kita! (Rosa, 2006:35)

Konflik individu lainnya dialami paling banyak oleh Mala saat bertemu tokoh-tokoh pahlawaan yang secara imajinatif hadir seperti Safian Cut Nyak Dhien, dan lainnya. Tokoh imajinatif tersebut sangat menentang dan marah kepada Mala karena ia sempat mengalami keputusasaan yang berlebihan. Akhirnya para tokoh imajinatif pahlawan tersebut membandingkan dengan perjuangan mereka melawan penjajah dahulu.

Konflik manusia dengan masyarakat atau kelompok dalam cerita digambarkan saat Aceh yang bagian dari Indonesia masih dijajah oleh oleh negara 
Belanda ataupun Portugis. Pejuang-pejuang perempuan Aceh pada akhirnya mampu menempati peran-peran strategis dalam peperangan. Kemenangan besar saat penjajah dapat diusir dari serambi mekah pun mereka raih dengan banyaknya korban nyawa dll. Contoh penggalan teksnya seperti Ketika kami hancur, Ketika suami dan anak-anak kami terbunuh dala peperangan melawan Portugis dan Belanda, semangat kami tak redup. Kami tetap tak ingin mati! Kami akan menyala! Saya memimpin para lelaki juga para janda bertempur dilautan tanpa kenal Lelah. Suami, anak, kerabat kami telah terbunuh. Kampung-kampung kami dihancurkan. ... / (Rosa, 2006:73)

Konflik manusia dengan alam diceritakan dalam cerita yaitu peristiwa awal gempa bumi yang melanda tokoh-tokoh dalam cerita. Mala dan keluarganya harus merasakan guncangan gempa yang sangat dahsyat sehingga tubuh mereka bergoyang sangat keras. Konflik ini berlanjut lantaran banak suara manusia lain yang berteriak air naik. Terjadilah peristiwa bencana alam terdahsyat di Aceh dalam cerita yaitu Tsunami. Tsunami ini merenggut banak nyawa dan meluluhlantahkan bumi Aceh hingga rata dengan tanah. Orang-orang yang masih hidup atau para relawan yang dating pun harus berjibaku dengan medan yang sulit serta bau mayat yang masih terasa sangat busuk menyengat. Contoh penggalan teksnya seperti (BERHENTI BERNYANYI) Mala, Mak merasa semua berguncang. Semua berguncang! Seperti ada raksasa datang. Seperti ada ribuan serdadu menyerbu (PANIK, JATUH) (hal 53)

Pembahasan selanjutnya adalah mengenai unsur budaya atau warna lokal aceh yang muncul dalam naskah drama Tanah Perempuan. Warna lokal Aceh sangat kental mewarnai cerita dalam naskah drama "Tanah Perempuan" karya Helvy Tiana Rosa. Hal tersebut dapat dilihat dari data di atas yang menggambarkan unsur budaya Aceh yang dilihat sepanjang cerita. Gambaran warna lokal Aceh yang tertuang dalam unsur bahasa, religi, mata pencaharian, sistem teknologi dan sisem organisasi dipaparkan oleh penulis naskah drama dengan berbagai teknik penceritaan.

Keunikan budaya yang muncul dalam unsur budaya Aceh terlihat dari berbagai aspek. Bahasa Aceh sebagai bahasa yang memperkaya bahasa daerah di Indonesia mempunyai ciri khasnya tersendiri. Dari unsur bahasa tersebut dipakai Helvy Tiana Rosa untuk memunculkan kekhasan tokoh-tokoh dalam cerita serta memperkuat latar cerita yang menunjukan warna lokal Aceh itu sendiri.

Berdasarkan data yang ditemukan, warna lokal bahasa Aceh ditemukan sebanyak 21 data dengan presentase 40,4\%. Unsur warna lokal bahasa Aceh sangat mendominasi kemunculannya dalam naskah drama Tanah Perempuan. Hal ini terlihat dari penyebaran kata berdialek daerah aceh dalam setiap cerita. Warna lokal bahasa Aceh tersebut muncul dalam bentuk kata, gabungan kata, kalimat, hingga berupa syair lagu. Kata paling sering muncul adalah lon yang berarti aku. Kata tersebut sangat sering muncul hampir di setiap percakapan terutama yang melibatkan tokoh Imran, Mala, Majid, Abu, dan Mak. Sedangkan kata-kata yang lain muncul tersebar di berbagai babak dalam drama. Contoh kata atau kalimatnya seperti rumoh geudong! (Rosa, 2006:26).

Warna lokal Aceh sistem teknologi dan peralatan ditemukan sebanyak 5 data dengan presentase $9,6 \%$. Sistem teknologi sebagai bagian analisis warna lokal 
Aceh memang muncul beberapa kali. Kemunculan unsur ini didominasi oleh ciri khas pakaian tradisional tokoh-tokoh yang ada dalam cerita naskah drama seperti pada tokoh Abu, Mak, dan Mala. Kemunculan alat lain yang mengindikasikan daerah Aceh memang tidak banyak dimunculkan oleh pengarang naskah drama ini. Contoh kata atau kalimatnya seperti MALA TERKEJUT MENEMUKAN DIRINYA DIKELILINGI TIGA PEREMPUAN BERPAKAIAN TRADISIONAL, LENGKAP DENGAN KERUDUNG DAN RENCONG (Rosa, 2006:92).

Sistem pencaharian yang menggambarkan warna lokal Aceh ditemukan sebanyak 4 data dengan presentase $7,7 \%$. Warna lokal ini muncul secara homogen jika dilihat dari data yang tertulis di tabel hasil temuan dari naskahnya. Sistem pencaharian yang dimunculkan dalam naskah tersebut banyak mengulas mengenai profesi guru yang direpresentasikan oleh tokoh Mala dan suaminya Majid. Tokoh Agam sebagai anak menggambarkan seorang anak Sekolah Dasar yang mulai tergoncang jiwanya akibat beberapa rentetan kejadian dalam cerita. Contoh kata atau kalimatnya seperti "Teman abang baru diangkat menjadi guru sejarah juga". (Rosa, 2006:31)

Sistem organisasi yang ditemukan ditemukan sebanyak 2 data dengan presentase $3,8 \%$. Warna lokal dari unsur ini tidak banyak dimunculkan oleh penulis. Warna lokal Aceh yang dimunculkan dari sistem organisasi ditunjukkan pada organisasi pemberontak dan hal yang terkait dengan hal tersebut. Penulis tidak ingin mengangkat organisasi yang ada dalam masyarakat Aceh karena ingin mengedepankan unsur warna lokal yang lainnya. Contoh kata atau kalimatnya seperti "Pada masa itu Ibu telah lulus dari Mahad Baitul Maqdis, akademi militer dengan intsruktur para tantara dari Kekhalifahan Turki Utsmani". (Rosa, 2006:74)

Warna lokal Aceh unsur religi ditemukan sebanyak sebanyak 20 buah dengan presentase $38,5 \%$. Sistem religi menjadi warna lokal Aceh yang kental kedua setelah aspek bahasa. Sistem religi yang dianut kebanyakan masyarakat Aceh terutama direfleksikan oleh para tokohnya adalah agama islam. Aspek dan unsur agama islam yang dimunculkan dalam cerita sangat kental karena setiap tokoh mempunyai pondasi yang kuat dan terlihat dalam ceritanya. Tokoh-tokoh dalam cerita banyak berujar mengenai kalimat Allah, hukum Allah, Takdir Allah, dan ajaran islam lainnya yang memperkuat bahwa tokoh-tokoh dalam cerita merupakan orang yang memeluk agama islam. Contoh kata atau kalimatnya seperti "Kita datang dari Allah, hidup untuk Allah, Kembali kepada Allah". (Rosa, 2006:94)

Jika dibedah dari sisi geografis, Provinsi Aceh memang berada yang paling ujung di barat Indonesia. Julukan yang melekat pada provinsi tersebut adalah Bumi Serambi Mekah. Hal tersebut sangat berkorelasi dengan isi cerita dalam drama lantaran data yang ditemukan dari aspek sistem religi terutama islam sangatlah kental dan kuat. Berbanding lurus dengan pernyataan di atas, Aceh mempunyai masyarakat yang mayoritas islam dan hal ini juga dimunculkan dari semua tokoh yang ada dalam isi cerita naskah drama Tanah Perempuan.

Syair atau lirik lagu yang muncul pun cukup memberikan ciri khas warna lokal Aceh setiap awal atau akhir sebuah adegan dan babak. Pengarang naskah, Helvy Tiana Rosa ingin memberikan sentuhan kesenian Aceh yang kuat lewat lagu berbahasa Aceh dalam naskah drama tersebut. bahasa-bahasa yang terujar dalam 
naskah drama sangat memberikan pesan tersendiri bahwa latar dan kejadian memang terdapat di sebuah tempat dengan gaya kehidupan Aceh yang sangat kental.

\section{SIMPULAN}

Berdasarkan ulasan pada hasil dan pembahasan penelitian ini, maka simpulannya adalah jenis konflik yang paling banyak dalam cerita adalah konflik manusia dengan manusia lain, diikuti konflik manusia dengan dirinya (batin), manusia dengan alam, dan konflik paling sedikit ditemukan adalah konflik manusia dengan masyarakat. Warna lokal Aceh yang paling banya muncul adalah unsur bahasa. Warna lokal terbanyak di bawah unsur bahasa adalah unsur religi, diikuti sistem teknologi dan peralatan, sistem pencaharian masyarakat, dan yang paling sedikit adalah sistem organisasi.

Telaah sastra pada naskah drama "Tanah Perempuan" yang menggunakan pendekatan warna lokal Aceh serta membedah konflik tokoh dapat memberikan pengetahuan tambahan bagi pembacanya, khususnya siswa, guru, mahasiswa, hingga pemerhati budaya. Diharapkan selanjutnya ada penulis yang membedah lebih dalam lagi seperti penelitian seperti ini.

\section{DAFTAR PUSTAKA}

Faruk. (2012). Metode penelitian sastra: Sebuah perjalanan awal. Yogyakarta: Pustaka Pelajar.

Hikmat, M. (2011). Metode penelitian: Dalam perspektif ilmu komunikasi dan sastra. Yogyakarta: Graha Ilmu.

Kluckhohn, C. (1953). Universal categories of culture. Antropology Today, A.L. Kroeber editor, Chichago University Press.

Minderop, A. (2005). Metode karakterisasi telaah fiksi. Jakarta: Yayasan Obor.

Pickering, P. (2006). How to manage conflict (Edisi Ketiga, Kiat Menangani Konflik. Terjemahan oleh Masri Maris), Jakarta: Erlangga.

Ratna, N. K. (2007). Sastra dan cultural studies: Representasi fiksi dan fakta. Yogyakarta: Pustaka Pelajar.

Rosa, H. T. (2006). Tanah perempuan: Naskah drama. Banda Aceh: Lapena. 